\title{
DEVELOPMENT OF LOW COST SMALL 3D SCANNER FOR ROBOTIC APPLICATIONS
}

\author{
Aleksandr Levin, Andrei Vorotnikov \& Yuri Poduraev
}
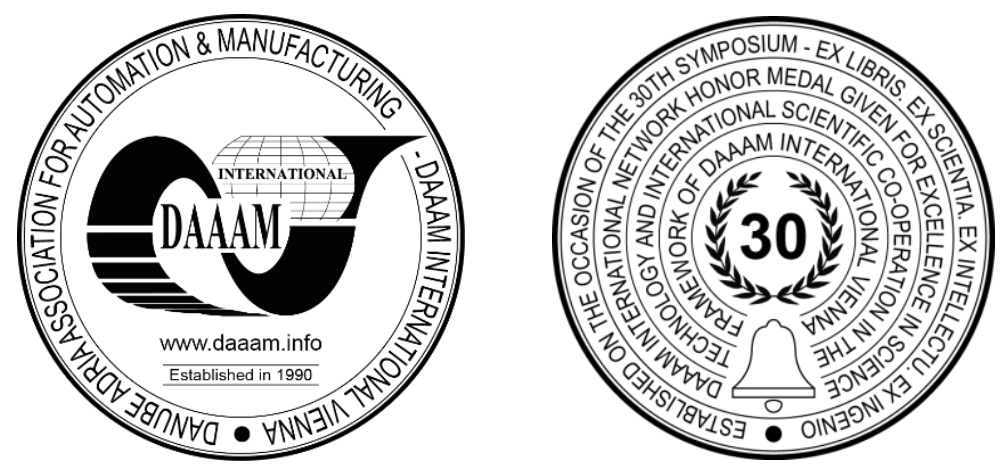

This Publication has to be referred as: Levin, A[leksandr]; Vorotnikov, A[ndrei] \& Poduraev, Y[uri] (2021). Development of Low Cost Small 3D Scanner for Robotic Applications, Proceedings of the 32nd DAAAM International Symposium, pp.0363-0368, B. Katalinic (Ed.), Published by DAAAM International, ISBN 978-3-902734-33-4, ISSN 1726-9679, Vienna, Austria

DOI: $10.2507 / 32$ nd.daaam.proceedings.053

\begin{abstract}
The integration of digital technologies, such as three-dimensional scanning, in production and everyday life can dramatically improve the quality of life. The low cost and ease of use of a 3D scanner can accelerate the implementation of this technology. In this paper, the existing solutions in the field of inexpensive $3 \mathrm{~d}$ scanners are considered. The development of a prototype 3D scanner based on the principle of laser triangulation and having 2 cameras is presented. A calibration method is described that allows reducing the number of images required for calibration. The algorithm for detecting the contour of the laser line in the image is shown. The accuracy of the developed 3D scanner is checked and conclusions are drawn about the work done.
\end{abstract}

Keywords: 3D scanner; stereo vision; 3D measurement; robot application.

\section{Introduction}

The ability to work with a digital copy of a real object is one of the most important needs of production and automation today. The reconstruction of a real object in the form of a digital copy in modern production is carried out using 3D scanning technologies. Unfortunately, 3D scanners have a high cost ( $\$ 1000$ and above). There is also a segment of scanners that differ in relatively low cost (about \$200). Usually, such scanners have a rotating platform that limits the size of the possible surface for scanning. For example, they do not allow to scan a part of a wall, or a person.

For robotic scanning tasks, manual scanners are inconvenient to use, since they take up a large amount of space, and stationary ones, as mentioned above, have limited scanning capabilities in terms of the size of the object being scanned. Robotic scanning is used in bioprinting [1], in maxillofacial surgery [2],[3],[4],[5],[6]. Scanning is also used in a wide variety of areas: wound scans [7], tire scans [8]. Virtual models of 3D scanners are also being created [9]. Studies have been conducted on the quality of such scanners [10]. But these scanners are used either permanently, or a large scanner is used on a robotic platform, which will not allow installing another unit of technological equipment on this robot. Therefore, it was decided to create a new device. To solve this problem, a miniature $3 \mathrm{~d}$ scanner was developed. The development included two main stages: prototype development and software development. The last stage, in turn, was divided into several more sub-stages: calibration of the camera, determining the position of the laser surface and obtaining the laser contour from the image. Then the developed 3D scanner was tested on trial samples to confirm its operability. 


\section{Prototyping}

There are several methods of 3D scanning. The most widespread are photogrammetry, stereometry, structured light [11] and laser triangulation. In this work, the structured light method was not used, since it requires a projector, which takes up a lot of space, and also has a relatively high cost. And for acceptable accuracy using stereometry and photogrammetry, expensive cameras are required. Therefore, the method of laser triangulation was chosen, but using two cameras, to increase the accuracy of scanning and increase reliability.

In this prototype, the Espada ENDSC2M endoscope was used as cameras (Fig. 1). Its characteristics are shown in Table 1. This camera has a small size and good quality. At the same time, the focal length of this camera does not change, which is necessary for the correct calibration of the internal parameters of the camera, and the laser module with the red laser line. The housing was made of plastic on a $3 \mathrm{~d}$ printer.

The cameras are installed at a distance B (set within $40 \ldots 100 \mathrm{~mm}$ ) and at an angle $\alpha$ relative to each other. The laser module is installed at an angle $\beta$ between the plane formed by the main axes of the cameras and the main axis of the laser module. The angles $\alpha$ and $\beta$ are adjusted so that the laser line completely fills the image width of each camera. The price of one camera is $\$ 5$, the price of a laser module is $\$ 2$, so the price of a scanner is $\$ 15$, which is an order of magnitude cheaper than any other similar scanning system. It is assumed that the user has a personal computer.

\begin{tabular}{|l|l|}
\hline Name of the parameter & Value \\
\hline Cable diameter & $4 \mathrm{~mm}$ \\
\hline Cable length & $1 \mathrm{~m}$ \\
\hline Lens diameter & $7.8 \mathrm{~mm}$ \\
\hline Size & $8 \times 46 \mathrm{~mm}$ \\
\hline Maximum resolution & $1280 \times 960$ pix. \\
\hline Weight & $120 \mathrm{~g}$ \\
\hline
\end{tabular}

Table 1. Camera characteristics

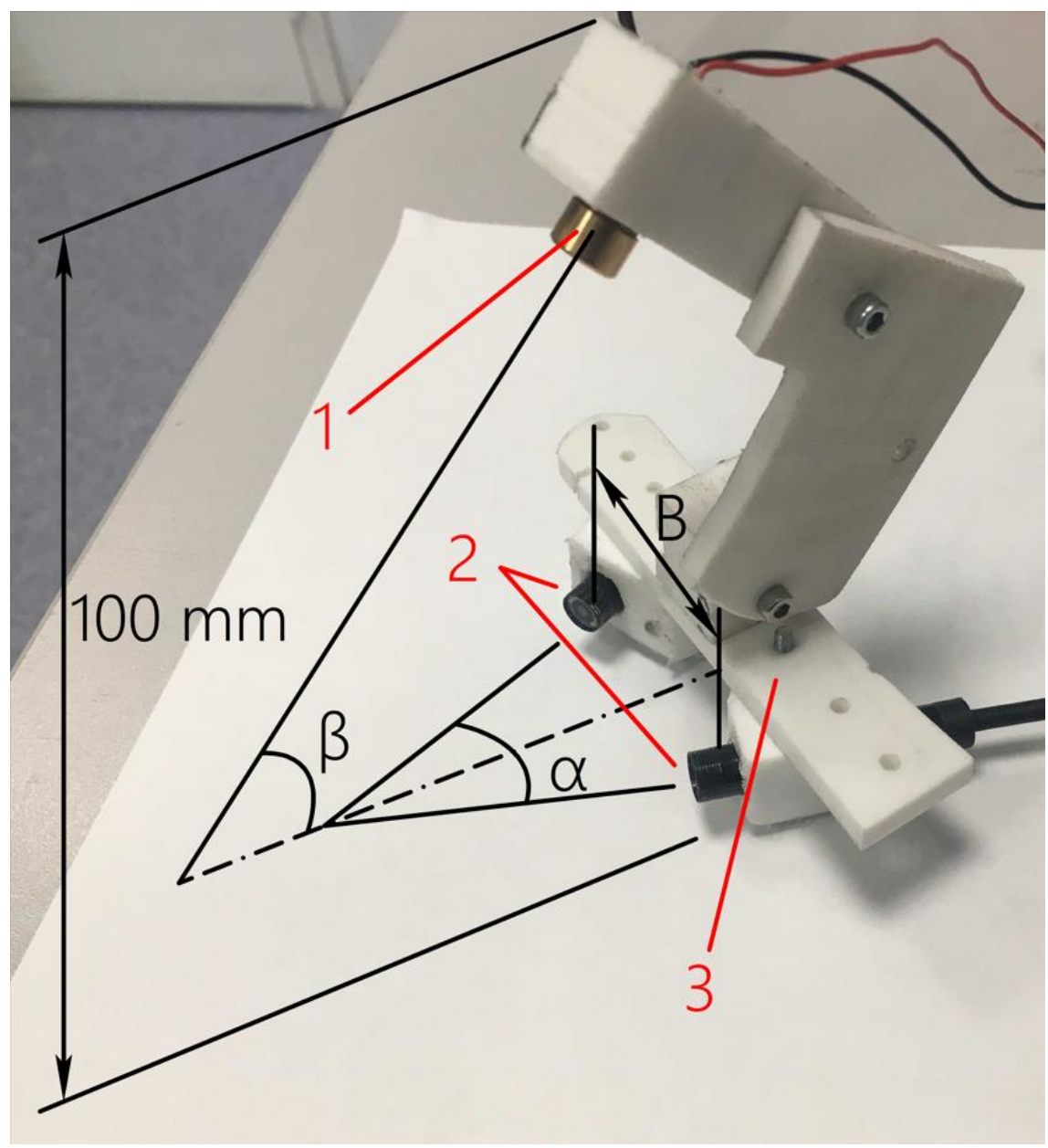

Fig. 1. Photo of the prototype ( 1 - laser module, 2 - cameras, 3 - housing, $\alpha$ - angle between the cameras, $\beta$ - angle between the laser scanning plane and the cameras) 


\section{Camera position}

To perform automatic scanning, the developed $3 \mathrm{~d}$ scanner is installed on a controlled platform (robot, machine, $3 \mathrm{~d}$ printer). To control such a device, software was developed in the $\mathrm{C} \#$ language. Also, this program performs all the calculations for the camera, allows to view the scanned model. To work with three-dimensional graphics, the OpenGL framework for C\# was used. The interaction of the user and the scanning system is carried out through the graphical interface (Fig. 2).

When scanning, the user sets the coordinates of the start and end points of the scan and the number of shooting points. The higher the number of shooting points, the higher the resolution of the model along the scan line will be. In order to increase the accuracy of scanning, the robot makes a stop before each image, and transmits the values about the coordinates to the computer at the time of shooting. At the same time, before taking a picture, the robot waits for a complete stop and only then sends a signal that it needs to be saved. The robot then proceeds to the next shooting point. Thus, the shooting speed depends on how far away the neighboring scanning points are. For example, if the distance between the points is 500 microns and 80 scanning points, the total scanning time will be about 100 seconds.

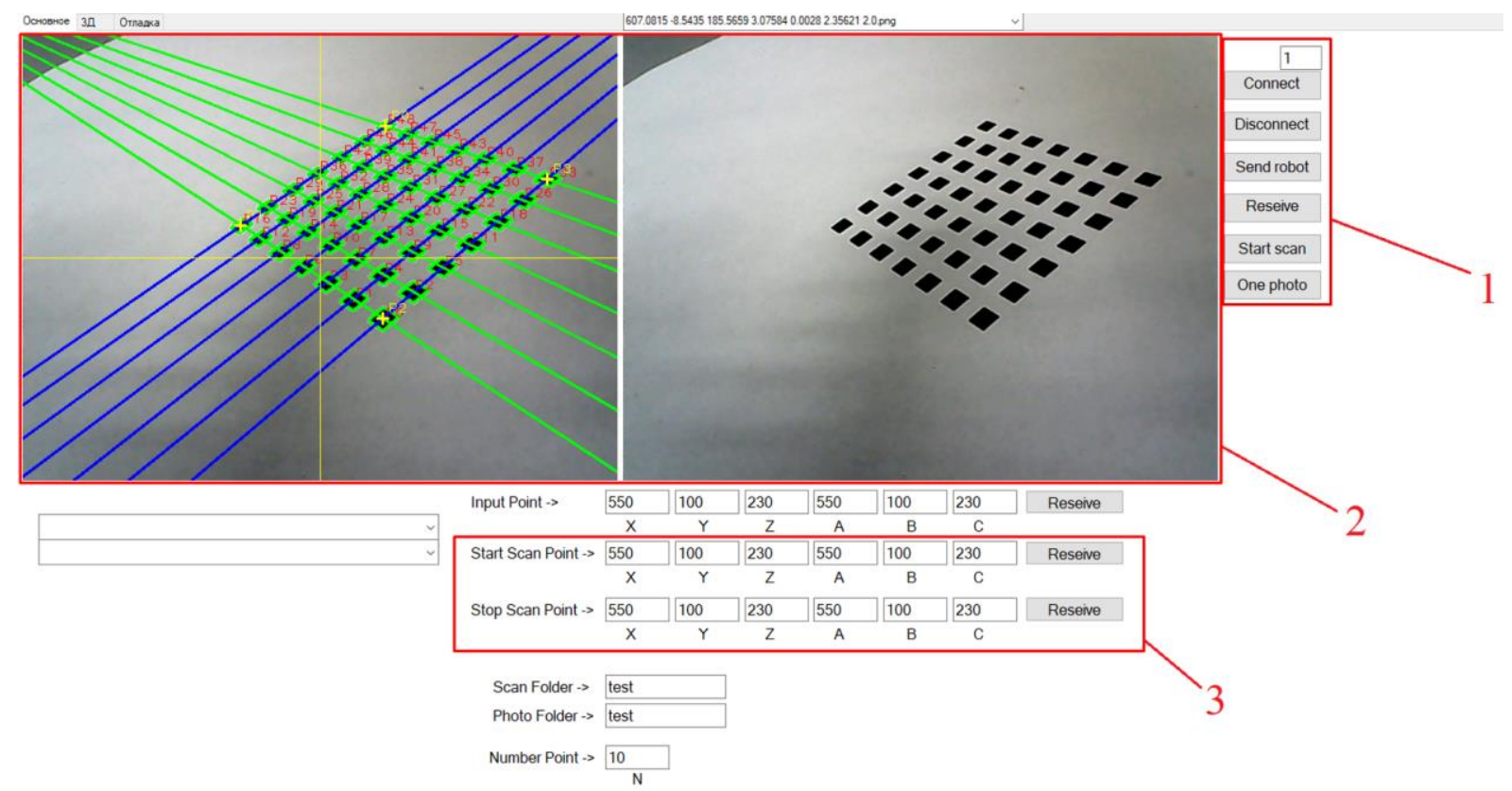

Fig. 2. The image of the user interface of the program (1 - The main control panel of the scanning system, 2-The window displaying the image from the cameras, 3-The panel for setting the coordinates of the start and end points of the scan)

In most cases, the calibration algorithm [12] for the 3D scanner camera of this price segment is used, implemented in the OpenCV library in a variety of languages: $\mathrm{C}++$, Python, $\mathrm{C \#}$. Calibration using this algorithm involves the use of about 10-15 images taken manually to determine the internal parameters of the camera. At the same time, there is a possibility that the program does not correctly calibrate the camera. A calibration algorithm has been developed that allows to calculate the camera position from four images of the calibration mark.

This result is achieved due to several simplifications: the distortion of these cameras is very small (they are calibrated in advance at the manufacturer's enterprise) and it was set in advance in which octant the camera is located relative to the coordinate system of the mark. An algorithm was also developed to automatically detect the mark on the image. To test the position detection algorithm, a virtual camera was created using OpenGL tools. A virtual experiment was conducted to determine the position of the calibration mark and compare it with the value of the camera position. The results of the experiment are shown in Table 2.

\begin{tabular}{|c|c|c|c|c|c|c|c|}
\hline $\mathbf{N}$ & $\mathbf{V x}$ & $\mathbf{C x}$ & $\mathbf{V y}$ & $\mathbf{C y}$ & $\mathbf{V z}$ & $\mathbf{C z}$ & $\boldsymbol{\delta} \mathbf{C}$ \\
\hline 1 & 0 & -0.4289 & 0 & 0.0557 & 113.475 & 113.3854 & 0.4417 \\
\hline 2 & 0 & -0.2552 & 0 & 0.0335 & 67.15 & 66.9896 & 0.3032 \\
\hline 3 & 0 & -0.3287 & 0 & 0.0433 & 87.295 & 87.1577 & 0.3588 \\
\hline 4 & 17.4133 & 17.7244 & -74.9847 & -74.7448 & 42.3033 & 42.5890 & 0.4857 \\
\hline 5 & 90.3101 & 90.2515 & -60.9709 & -61.2016 & 78.5054 & 78.5675 & 0.2459 \\
\hline
\end{tabular}

Table 2. Checking on a virtual model $(\mathrm{Vx}, \mathrm{Vy}, \mathrm{Vz}$ - the value of the camera coordinate, $\mathrm{Cx}, \mathrm{Cy}, \mathrm{Cz}$-the calculated value of the camera coordinates, $\delta V C$ - the distance between points) 
For the experiment, 5 different positions of the calibration mark were selected. Next, we determined how much the calculated coordinates differ from those set virtually:

$$
\delta V C=\sqrt{\left(V_{x}-C_{x}\right)^{2}+\left(V_{y}-C_{y}\right)^{2}+\left(V_{z}-C_{z}\right)^{2}}
$$

Then it was determined in the average distance between these points:

$$
\overline{\delta V C}=\sum_{i=1}^{5} \delta V C_{i}=0.36706
$$

This error is caused by the discreteness of the pixel image.

\section{Detection laser line}

The laser line is represented in the image as a light strip. We are interested in the contour of the object, that is, a certain clear line. The lower border of the light strip was chosen as the contour in the image. The image of the line, depending on the object, may have breaks and noises. To build a 3D model that is closest to reality, it is necessary to eliminate these problems. First of all, the image was binarized according to a certain threshold value set by the user. It depends on the ambient lighting, camera settings, scanner configuration (distance $B$, angles $\alpha, \beta$ ).

To obtain the lower contour of the light strip in each column of the image, only the lowest pixel was left. Figure 3 shows areas where there is not a single pixel, each such area was filled with a line connecting its extreme points. Then the entire contour is smoothed so that the model surface is smooth. The coordinate of the $i$-th pixel during smoothing is calculated as follows:

$$
p_{i}=\sum_{i=-k / 2}^{k / 2} p_{i+k}
$$

In this expression, $k$ is the smoothing width, the higher the value of this parameter, the smoother the model will turn out. But at the same time, sharp corners will also be rounded off. Figure 3 shows the step-by-step operation of the algorithm for determining the contour from the image.

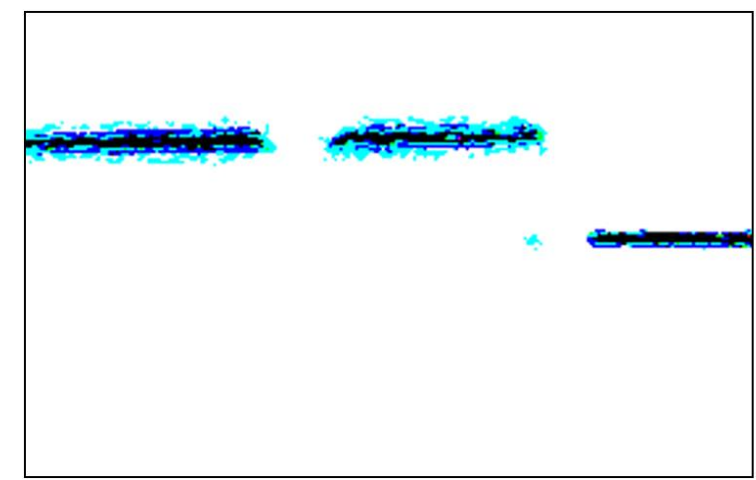

a)

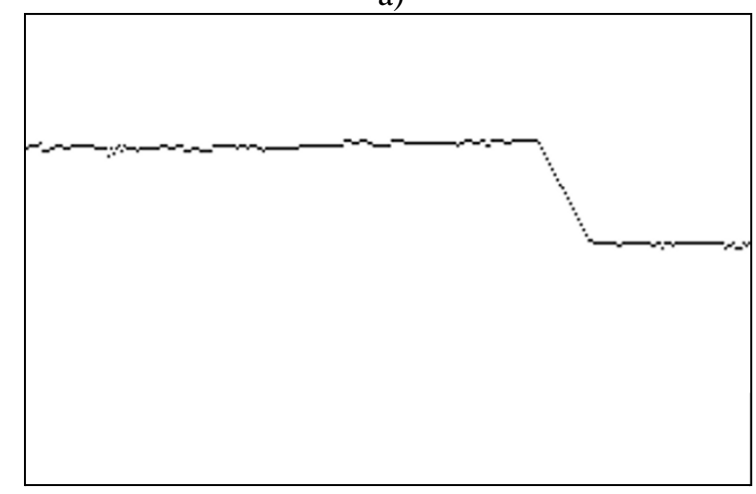

c)

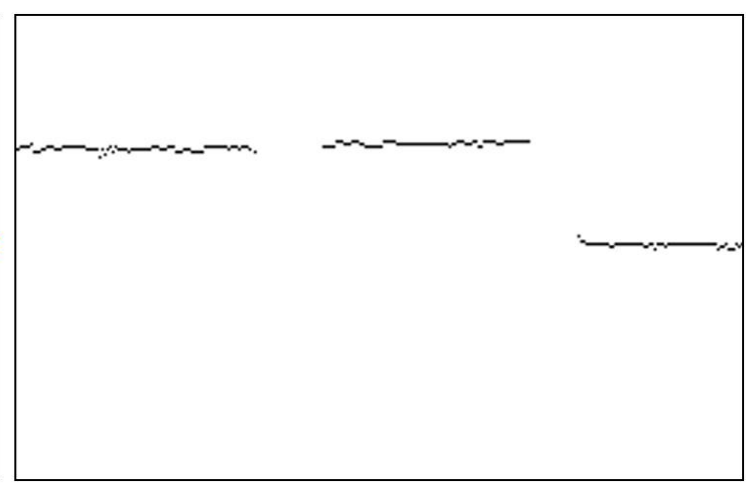

b)

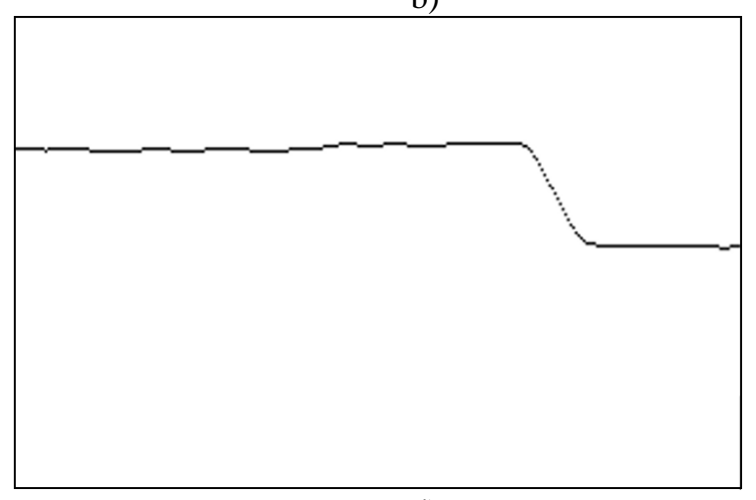

d)

Fig. 3. a) The image of the laser line after binarization, b) The definition of only one pixel in each column, c) The contour after filling in the missing sections, d) the contour after applying smoothing 


\section{Measuring accuracy}

The developed scanner was tested by scanning two test samples. For testing, 2 objects were selected as an example (Fig.4) made of different materials - metal and plastic. The measurement results are shown in Table 3. An example of the scanned parts is shown in Figure 4. The measurement was performed for 3 different distances between the cameras.

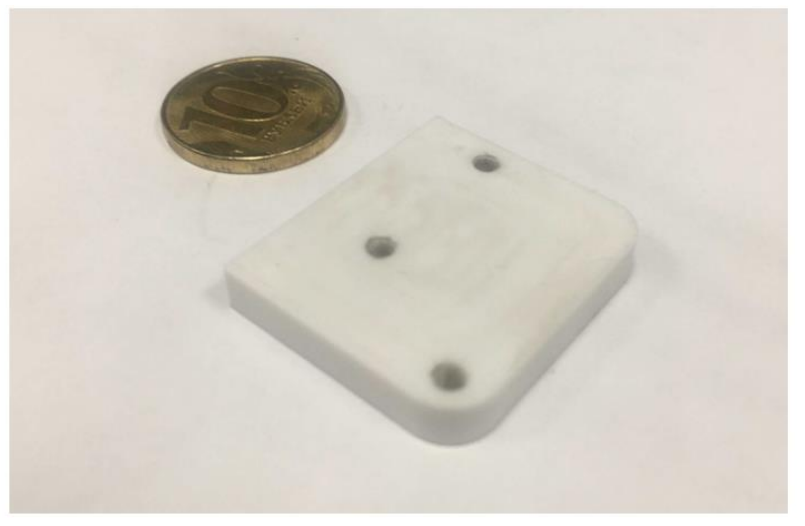

a)

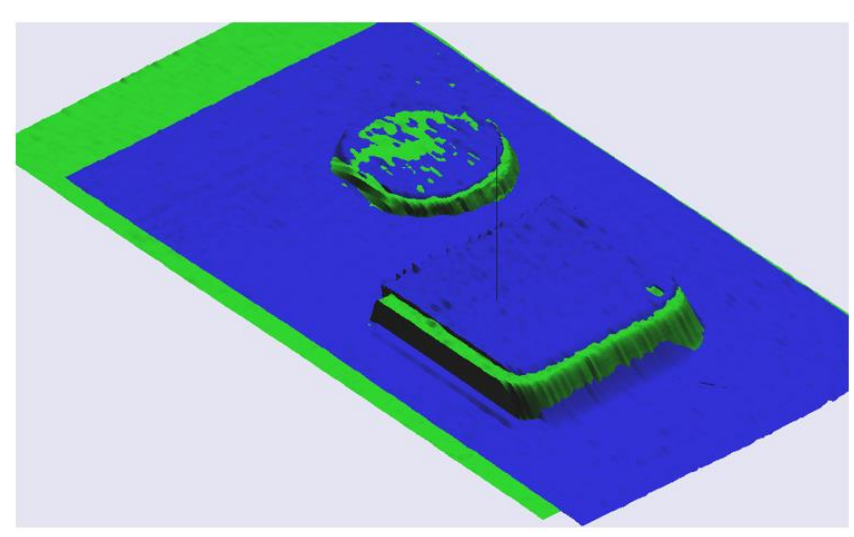

b)

Fig. 4. a) the scanned object b) the recreated $3 \mathrm{~d}$ model (green is the first camera, blue is the second camera)

\begin{tabular}{|c|c|c|c|c|}
\hline & $\begin{array}{c}\text { Measured values (Caliper, } \\
0.1 \mathrm{~mm} \text { error })\end{array}$ & $\begin{array}{c}\text { 3D model values }(\mathrm{B} \\
=42 \mathrm{~mm})\end{array}$ & $\begin{array}{c}\text { 3D model values }(\mathrm{B} \\
=68 \mathrm{~mm})\end{array}$ & $\begin{array}{c}\text { 3D model values } \\
(\mathrm{B}=102 \mathrm{~mm})\end{array}$ \\
\hline Length, $\mathrm{mm}$ & $31.9 \ldots 32.0$ & $31.5 \ldots 32.5$ & $31.05 \ldots 32.8$ & $30.4 \ldots 33.4$ \\
\hline Width, $\mathrm{mm}$ & $27.9 \ldots 28.0$ & $27.5 \ldots 28.5$ & $27.1 \ldots 28.8$ & $26.6 \ldots 29.3$ \\
\hline Height, $\mathrm{mm}$ & $5.4 \ldots 5.5$ & $5.2 \ldots 5.8$ & $5.1 \ldots 5.8$ & $4.9 \ldots 6.1$ \\
\hline
\end{tabular}

Table 3. Results of scanning the test part (B - the distance between the cameras)

It can be seen from the scanning results that the scanner is able to obtain 3D models with an uncertainty [13] of about 1 $\mathrm{mm}$, which is acceptable for a $\$ 15$ scanner.

\section{Conclusion}

The task of this work was to develop a $3 \mathrm{~d}$ scanner with a low cost and acceptable resolution. The existing solutions were reviewed, and it was concluded that it is necessary to develop own more inexpensive solution. We managed to solve this problem by choosing a laser triangulation method for this scanner, as well as two very low-cost cameras. Software has also been developed that allows to control both the movement of the platform and the shooting of the camera. The introduction of such a device will accelerate the development of computer technology. Due to the low cost, the number of consumers of the technology will expand, as well as the number of people who will want to develop it further. It is also possible that this will lead to a slight drop in the prices of professional scanners.

In the future, it is planned to improve one of the aspects of the software, namely the software post-processing of the scanned model. For example, face recognition, increasing the accuracy of the model by improving the algorithms for calculating the contour.

\section{Acknowledgments}

Scientific Research by Educational Organizations in 2020-2022 Project under Grant NoFSFS-2020-0031.

\section{References}

[1] Levin, A.; Vorotnikov, A. \& Poduraev, Y. (2020). A Robotic System for Hydrogel 3D Printing on Complex Surfaces, pp. 0793-0799. DOI:10.2507/31st.daaam.proceedings.110

[2] Vorotnikov, A. A.; Klimov, D. D. K. \& Bazykyan, E. A. (2018). Criteria for Comparison of Robot Movement Trajectories and Manual Movements of a Doctor for Performing Maxillofacial Surgeries, International Journal of Mechanical Engineering and Robotics Research, Vol. 7, No. 4, pp. 361-366. DOI:10.18178/ijmerr.7.4.361-366

[3] Vorotnikov, A. A.; Klimov, D. D. \& Chunihin, A. A. (2017). Cutting velocity accuracy as a criterion for comparing robot trajectories and manual movements for medical industry, Mechanics \& Industry, Vol. 18, No. 7, pp. 712. DOI:10.1051/meca/2017047 
[4] Chunikhin, A. A.; Bazikyan, E. A. \& A. A.; Klimov, D. D. (2019). Comparative experimental assessment of the accuracy of nanosecond laser surgery of the oral cavity when the instrument is moved by a robotic complex and a surgeon, Russian Open Medical Journal, Vol. 8, No. 3, pp. e0307. DOI:10.15275/rusomj.2019.0307

[5] Vorotnikov, A. A.; Buinov, M. A. \& Chunihin, A. A. (2016). Standard Deviation from the Average Cutting Velocity as a Criterion for Comparing Robot Trajectories and Manual Movements of a Doctor for Performing Surgical Operations in Maxillofacial Surgery, International Journal of Mechanical Engineering and Robotics Research, Vol. 7, No. 2, pp. 319-323. DOI:10.18178/ijmerr.7.3.319-323

[6] Chunikhin, A. A.; Poduraev, Y. V. \& Bazikyan, E. A. (2017). Efficiency Assessment of Nanosecond Laser Robotic Maxillofacial Area Surgery in Experiment, Sovremennye Tehnologii v Medicine, Vol. 9, No. 4, pp. 123. DOI:10.17691/stm2017.9.4.15

[7] Zhao, Y. M.; Currie, E. H.; Kavoussi, L.; Rabbany, S. Y. (2021). Laser scanner for 3D reconstruction of a wound's edge and topology, International Journal of Computer Assisted Radiology and Surgery. DOI:10.1007/s11548-02102459-1

[8] Frosio, I.; Borghese, N. A.; Tirelli, P.; Venturino, G.; Rotondo, G. (2011). Flexible and low cost laser scanner for automatic tyre inspection, 2011 IEEE International Instrumentation and Measurement Technology Conference, IEEE, pp. 1-5. DOI:10.1109/IMTC.2011.5944190

[9] Lima, J.; Gonçalves, J.; Costa, P. J. (2015). Modeling of a Low Cost Laser Scanner Sensor, pp. 697-705. doi:10.1007/978-3-319-10380-8_67

[10] Polo, M.-E.; Felicísimo, Á. M. (2012). Analysis of Uncertainty and Repeatability of a Low-Cost 3D Laser Scanner, Sensors, Vol. 12, No. 7, pp. 9046-9054. DOI:10.3390/s120709046

[11] Straub, J.; Kerlin, S. (2014). Development of a Large, Low-Cost, Instant 3D Scanner, Technologies, Vol. 2, No. 2, pp. 76-95. DOI:10.3390/technologies2020076

[12] Zhang, Z. (2000). A flexible new technique for camera calibration, IEEE Transactions on Pattern Analysis and Machine Intelligence, Vol. 22, No. 11, pp. 1330-1334. DOI:10.1109/34.888718

[13] Vorotnikov, A.; Romash, E. \& Poduraev, Y. (2016). Uncertainty Estimation of Axes Direction Determination of Industrial Robot Using an Ellipsoid Concentration Model, pp.0480-0486. DOI:10.2507/27th.daaam.proceedings.072 